choices between personal income and service development, can only be part of the solution.

Addressing the inverse care law is made difficult by three other problems: first, the front line of this part of the NHS is largely hidden from external view, as a result of its geographically scattered nature, the lack of evidence, limited nature of routine clinical information, and the rarity of analyses aggregating practices according to the nature of the populations they serve. ${ }^{6}$ Second, current orthodoxy on inequalities in health, maintained largely by doctors, researchers, and policy advisers without clinical contact or insight, does not generally support policies to increase the volume and quality of health care in poor areas. Third, the challenge affects only a minority of doctors and practices, whose populations' needs tend to get short shrift when the needs and interests of the wider profession are an issue. In summary, despite plentiful rhetoric about addressing inequalities, there is a dearth of well informed, influential, and powerful champions to address inequalities in NHS primary care.

To its credit, the Quality and Outcomes Framework (QOF) engaged almost $100 \%$ of practices, at substantial cost, with improvements in information and organisation that will continue to be beneficial. Although the QOF largely ironed out social gradients in incentivised quality markers, it did little to change gradients for markers that were not incentivised..$^{13}$ In general, the new contract offers little to address inverse care ${ }^{14}$ and is likely to be more divisive as its targets become more demanding.

If Bevan were in charge of the NHS today, with its new circumstances and challenges, would he not argue that the service should be seen at its best, and that professional careers and rewards should be most attractive where needs are greatest? That is a challenge, not only to our generosity as a society, but also to our ability to imagine structural solutions to the inverse care law.

The NHS fairy story is that all interests are part of the solution; none is part of the problem, but the careful statistics of the Registrar General tell a different tale.

\section{Graham Watt,}

Professor of General Practice,

University of Glasgow, Glasgow

\section{REFERENCES}

1. Starfield B, Shi L, Macinko J. Contribution of primary care to health systems and health. Milbank Q 2005 83(3): 457-502.

2. Bevan A. In place of fear. London: Heinemann, 1952.

3. Bunker JP. Medicine matters after all: measuring the benefits of medical care, a healthy lifestyle, and a just social environment. London: Nuffield Trust for Research and Policy Studies in Health Services, 2001.

4. Watt G. The inverse care law today. Lancet 2002; 360(9328): 252-254.

5. Hart JT. The inverse care law. Lancet 1971; 1(7696): 405-412.

6. Sutton M, Mackay D, Watt G. Deprivation and volunteering by general practices: cross sectional analysis of a national primary care system. BMJ 2005: 331(7530):1449-1451.

7. Esmail A. Asian doctors in the NHS: service and betrayal. Br J Gen Pract 2007; 57(543): 827-834.

8. Pollock AM. NHS plc: the privatization of our health care. London: Verso, 2004.

9. Pollock AM, Price D, Viebrock E, et al. The market in primary care. BMJ 2007; 335(7618): 475-477.

10. Watt G. Not tonight Josephine: on private incursions into primary care. Br J Gen Pract 2006; 56(533): 974-975.

11. Hart JT. The political economy of health care: a clinical perspective. Bristol: Policy Press, 2006.

12. Mercer SW, Watt GC. The inverse care law: clinical primary care encounters in deprived and affluent areas of Scotland. Ann Fam Med 2007; 5(6): 503-510.

13. Elder R, Kirkpatrick M, Ramsay W, et al. Measuring quality in primary medical services using data from SPICE. Edinburgh: NHS National Services

Scotland/NHA Quality Improvement Scotland, 2007. www.indicators.scot.nhs.uk/SPICE_Report_July_2007.p df (accessed 10 June 2008).

14. Guthrie B, McLean G, Sutton M. Workload and reward in the Quality and Outcomes Framework of the 2004 general practice contract. Br J Gen Pract 2006; 56(532): 836-841.

DOI: 10.3399/bjgp08X302952

ADDRESS FOR CORRESPONDENCE

\section{Graham Watt}

University of Glasgow, General Practice and Primary Care, 1 Horselethill Road, Glasgow, G11 5AW.

E-mail:gcmw1j@clinmed.gla.ac.uk

\title{
Your general practice environment can improve your community's health
}

The vast majority of GPs believe that they can achieve excellence in their practice when they have developed the optimal mix of knowledge, experience, skills, attitudes, and effective consultation techniques. Unfortunately, what many GPs appear to forget is that the consultation, the very heart of their clinical practice, happens within a physical space.

Not surprisingly, given the traditional emphasis on the aforementioned more 'practical' clinically-focused attributes of general practice, a gap exists in understanding the life-enhancing potential of physical space. However, this gap is now beginning to close. The recently conducted research by Rice et $a l^{1}$ (published in this issue) highlights several of the vitally important practice improvements that the sensitively designed physical environment can contribute.
This new investigation by Rice et al must be commended for its intention to begin to close a gap in the research literature. Specifically, this research makes three important and very practical contributions to the literature. Firstly, it describes a range of tangible outcomes that the physical environment can be used to improve, as well as describing the actual environmental elements that were used to achieve these improvements. 
Secondly, this research was conducted within GP surgeries, which enhances the direct relevance and possible generalisability. Finally, is the simple fact that the research was conducted in the UK, which serves to situate it and its findings precisely where they are needed, and is beginning to close a research gap in the UK.

However, both a strength and a weakness of this research is its narrow focus on the role of the physical environment. The strength comes from the very nature of conventional scientific inquiry, which necessitates the inclusion of certain variables, and the exclusion of others. Here the physical environment has been included and the social environment excluded. This is perhaps a weakness, as excluding the social environment is an analytical abstraction and fails to reflect real-world conditions.

In the real world, of course, outcomes that are influenced by the physical environment are always mutually contingent upon the interaction of the social environment and vice versa. A weakness in this research is that it is silent on this point of the contingent interrelationship between physical and social space, as well as not providing a more broad discussion about the overall influence of the environment in general.

For example, there are three distinct types of environment. Firstly, the physical environment, which includes the built environment and the natural environment. In a general practice, this includes the building and its site, all of the rooms and spaces in the building, and all of the physical components in these rooms and spaces.

The second type of environment is 'social space'. Social space is produced when an individual interacts with another individual, a group, or even the physical environment. For example, in all of the moments that a GP interacts with a patient, social space is actively being coproduced.

'Generative space' is the third type of environment. Generative space includes both social space and the physical environment. It is social space that is informed, conditioned, and reinforced by the physical environment. Generative space is generative as it encourages, supports, and reinforces improvements to health and wellbeing; also, by its very nature, generative space is progressively life-enhancing.

Generative space is a newly emerging concept in the design of healthcare environments, which is advancing beyond earlier concepts, such as 'healing environments' and 'evidence-based design', that were based exclusively upon the physical environment (http://www. thecaritasproject.info/leading.html). A distinct advantage of this new approach, over that of merely using physical and/or social space to produce improved outcomes, is that the improved outcomes are sustainable. In this case, 'sustainable' means that the improvements are not just episodic, rather, the improvement continues to progress over time.

An example of generative space, being used in a UK-based general practice is described in an account provided by Jacques Mizan. ${ }^{2}$ Mizan is a London-based practicing GP who has founded The Space Works (http://healthcaredesign. squarespace.com), a pioneering research unit that serves as a resource on how the environment can improve health outcomes in general practice and community health settings.

Notwithstanding this brief critique of the Rice et al research, the more important matter to consider is the practical application of its findings, insofar as they might inform the mainstream practice of GPs. There are two particularly compelling reasons why the environment is crucially important to supporting excellence for practicing GPs.

Firstly, and perhaps most importantly, a sensitively-executed general practice environment will produce an extremely favourable 'return on investment' that can be quantified in terms of 'an improvement in patients' perception of patient-doctor communication, reduced patient anxiety in the surgery, and increases in patient and staff satisfaction'.'

Secondly, in every sense, the 'writing is on the wall'. The RCGP practice accreditation process, currently being piloted ahead of a national roll out, specifically mentions the physical environment and patient experience as a key assessment target. ${ }^{3}$ Additionally, the revised version of the Health Building Notes, currently being drafted for release later this year, also acknowledges the value of a sensitively-designed environment ( $\mathrm{J}$ Mizan, personal communication, 2008). Clearly, the RCGP and the NHS expect change and GPs will be expected to learn how to deliver it.

Very simply, the bottom line is this: an emerging body of research suggests that the environment does influence the consultation, the decision-making process within it, diagnostic effectiveness, and clinical outcomes. Consequently, an ethical imperative is beginning to surface that engages with contemporary notions of more collaborative working and transcends the more traditional issues relating to the ownership of facilities. Within any given surgery or primary care centre, it is everyone's job to work actively towards improving outcomes and the environment is increasingly becoming recognised as a powerful instrument to enhance the overall effectiveness of these collective efforts.

GPs might naturally be concerned about additional costs that could result from upgrading the environment. However, any concerns that substantial additional expenditures are required to improve outcomes can be minimised. It has been demonstrated that many environmental elements that support improved outcomes do not increase construction or refurbishment costs. For example, using a paint colour that is known to be anxiety-reducing costs no more than a bucket of paint that is any other colour. Indeed, the labour cost is the same in either case.

Other types of life-enhancing environmental elements might add a slight cost premium, such as windows that can be opened. However, when the choice of these elements is grounded in the findings of quality research, the return on investment for the additional cost increment can be justified within the overall life cycle performance of the environment. A newly-found freedom can be achieved in shifting our understanding of these expenditures from the more traditional paradigm of non-recoverable costs to thinking of them, rather, as 'investments' that will produce enhanced outcomes.

This notion of improving health with the environment is not a flavour-of-the-month 
fad. On the contrary, there is a wellestablished and growing international transdisciplinary body of knowledge. In the US, for example, the entire healthcare sector has been transformed during the past 25 years as a result of the application of this research.

The Center for Health Design (http://www.healthdesign.org), based in California, is a recognised international resource that has compiled much of this research and has documented its influence on the overall healthcare industry. Its more significant resources include the meta-study by Ulrich and Zimring $^{4}$ and publication of the journal Healthcare Design.

Indeed, closer to home and within the Greater London area, there is a legacy of primary care practices that have intentionally and successfully used the environment to improve health: The Pioneer Health Centre and The Finsbury Park Health Centre (both 1930s); the Bromleyby-Bow Healthy Living Centre (established in 1984) and the Lambeth Community Care
Centre (established in 1985).

In the realm of general practice, the active cultivating of 'generative space' for patients and their families, staff, clinical practitioners, and the overall local community can be aspired to as a new benchmark. Perhaps the establishment of this benchmark in the mainstream is a decade, or so, into the future. Nevertheless, it is already showing up on the radar screens of the top-of-the-class practitioners, and the leaders in the field are investing their time and money to learn more about this.

As idealistic as it might sound today, the future will see 'generative' GP practices dotting the landscape like lighthouses punctuating the nightime seacoast. As far as their 'generative' beams of lifeenhancing professional practice reach deeply into the very workings of their respective local communities, they will function as health and wellbeing generators, transforming their contiguous local economies into actively flourishing hives of creative human enterprise.

\section{Wayne Ruga,}

International Executive Healthcare Architect, based in Manchester. Founder and President of The CARITAS Project.

\section{REFERENCES}

1. Rice G, Ingram J, Mizan J. Enhancing a primary care environment: a case study of effects on patients and staff in a single GP practice. Br J Gen Pract 2008; 58 : $465-470$

2. The Caritas Project. The leading by design research project. US: The Caritas Project, 2008. http://www. thecaritasproject.info/leading_jacques.html (accessed 05 Jun 2008).

3. Royal College of General Practitioners. RCGP confirms next steps for practice accreditation scheme. London: RCGP, 2006.

4. Ulrich $\mathrm{R}$, Zimring $\mathrm{C}$. The role of the physical environment in the hospital of the 21st century: a once-in-a-lifetime opportunity. http://www.healthdesign.org/ research/ reports/physical_environ.php (accessed 2 Apr 2008).

DOI: 10.3399/bjgp08X302961

\section{ADDRESS FOR CORRESPONDENCE}

Wayne Ruga,

Founder and President, The CARITAS Project, PO Box 4309, Deerfield Beach, Florida 33442, US.

Email: wruga@post.harvard.edu

\section{Do you have your own doctor, doctor? Tackling barriers to health care}

Doctors are more at risk of mental illhealth than the general population. ${ }^{1}$ The risk of suicide is higher than the general population, especially among GPs, anaesthetists, and psychiatrists. ${ }^{2}$ Studies from North America suggest that $8-18 \%$ of doctors will be affected by drug or alcohol abuse during their lifetime. ${ }^{3}$ So the way that doctors do or don't access health care is important - for them, their families, their colleagues, and ultimately, for their patients. An article in this issue ${ }^{4}$ reviews the literature on health behaviours of doctors and the barriers they experience in accessing care.

The review is timely in that the 2007 white paper, Trust, Assurance and Safety the Regulation of Health Professionals in the 21 st Century ${ }^{5}$ proposed a strategy for improving the health of health professionals. This will include appropriate prevention and early intervention for health concerns, promoting easier uptake of services and assuring confidentiality. In 2006 the Chief Medical Officer ${ }^{6}$ recognised deficiencies in the provision of care to doctors impaired by mental health and addiction problems. In addition, the Department of Health published a report this year on mental ill health in doctors; ${ }^{7}$ this was a response to the inquiry ${ }^{8}$ into the suicide of a young psychiatrist with serious mental illness who received suboptimal care.

Dating back to 1994, a variety of reports in the UK, from the Nuffield Trust, $, 10,11$ the General Medical Council $(\mathrm{GMC}),{ }^{12}$ and the British Medical
Association $(B M A)^{13}$ have identified the particular health needs of doctors and the barriers they experience in accessing care.

\section{THE BARRIERS}

The review by Kay et a/4 notes that there is little data on doctors' health access behaviours and the barriers they experience. It does, however, provide some useful pointers. Factors that affect access to health care by both doctors and their patients include self-care, concerns about confidentiality, lack of time, costs in accessing care, fear, and embarrassment about the triviality of the condition. Those with mental health problems experience these barriers more severely.

Additional barriers for doctors identified 